\title{
Surface Characterization of Titanium Implants Treated in Hydrofluoric Acid
}

\author{
Danila M. Korotin ${ }^{1}$, Stefan Bartkowski ${ }^{2}$, Ernst Z. Kurmaev', Manfred Meumann², \\ Eugeniya B. Yakushina ${ }^{3}$, Ruslan Z. Valiev ${ }^{3}$, Seif O. Cholakh ${ }^{4}$ \\ ${ }^{1}$ Institute of Metal Physics, Russian Academy of Sciences-Ural Division, Yekaterinburg, Russia; ${ }^{2}$ Faculty of Physics, University of \\ Osnabrueck, Osnabrueck, Germany; ${ }^{3}$ Institute of Physics of Advanced Materials, Ufa State Aviation Technical University, Ufa, Rus- \\ sia; ${ }^{4}$ Ural Federal University, Yekaterinburg, Russia. \\ Email: danila.korotin@gmail.com,kurmaev@ifmlrs.uran.ru
}

Received October $4^{\text {th }}, 2011$; revised November $19^{\text {th }}, 2011$; accepted December $20^{\text {th }}, 2011$

\begin{abstract}
The results of XPS measurements of commercially pure titanium (cp-Ti) before and after chemical treatment are presented. We have measured XPS spectra of core levels (Ti 2p, O 1s, C 1s, F 1s) and valence bands of coarse-grained $c p$-Ti before and after standard acid treatment accepted in dentistry (in 1\% HF and $40 \% \mathrm{HF}$ for $1 \mathrm{~min}$ ). It is found, that acid treatment of $c p$-Ti reduces the content of hydrocarbons increasing the surface energy and bio-compatibility of Ti-implants. On the other hand, it is fixed that oxygen concentration on the surface of the acid treated $c p-\mathrm{Ti}$ is much higher than for the untreated sample, because the acid treatment removes the contaminated surface layers, increases their reactivity, provides a better passivation and formation of thick protecting $\mathrm{TiO}_{2}$ layer.
\end{abstract}

Keywords: Commercially Pure Titanium; Surface Composition; Hydrofluoric Acid; Surface Characterization; Biocompatibility

\section{Introduction}

The materials for medical implants are required to be biocompatible, not toxic and also should not cause allergic reactions. They must have high ultimate strength and yield points with desirable low density and low modulus of elasticity. Commercially pure $\mathrm{Ti}(c p-\mathrm{Ti})(99.85 \% \mathrm{Ti})$ meets all these requirements and is considered to be one of the most biocompatible and corrosion resistant metals available for medical applications.

The reaction of biological tissue to biomaterial surfaces and the formation of bonds between implant surfaces and biological tissues are largely dependant on the existence of a high surface energy on the implant surface. Contamination of biomaterial surfaces with hydrocarbons, molecules and elements can reduce the surface energy and, thereby, also the potential bio-to create these components, incorporating the applicable criteria that follow compatibility of an implant. It is known, that commercially pure titanium is highly reactive and its surface composition is substantially different from the bulk [1] and forms spontaneously, within seconds, several oxides when exposed to air, water, or an aqueous biological environment among which $\mathrm{TiO}_{2}$ is the most common one [2].

The interaction of the implant with its biological environment, the formation of material-tissue interface and the long-term success or failure of the integration in the body is now realized to be strongly connected with the surface properties of the implant device. Even within one type of material, such as $c p-\mathrm{Ti}$, the degree of integration depends on the quality of the surface. It is found, that fluoride-modification of titanium medical (dental) implants (performed by chemical treatment in HF-hydrofluoric acid) provides the better implant attachment and improves bone response [3], reduces the healing time needed before loading, as well as significantly improves the bone-to-implant contact [4]. In the present paper the results of surface characterization of $c p$-Ti after chemical treatment in the hydrofluoric acid (HF) are presented. We have measured XPS core levels (Ti 2p, O 1s, C 1s, F 1s) and valence band spectra before and after standard chemical treatment (in 1\% HF, 1 min and in $40 \% \mathrm{HF}, 1$ min) which is used in the dentistry before implantation. For each set of measurement the ion etching (with $\mathrm{Ar}^{+}$ ions) was performed in a step by step mode with etching intervals of few minutes (from 1 to $10 \mathrm{~min}$ ). In this way, the detailed study of composition and chemical state of titanium and oxygen (as well as carbon and fluorine) is performed, what gives us the full information about the surface and the near-surface layers of $c p$-Ti before and after chemical treatment. 


\section{Experimental}

Commercially pure titanium $c p$-Ti Grade 4 (Ti: base, C: $0.052 \%$, O: $0.34 \%$, Fe: $0 \%$, N: $0.015 \%$ (wt $\%)$ ) was employed to conduct the research (Figure 1). The coarse grained $c p$-Ti in the form of discs $(10 \mathrm{~mm}$ dia and $1 \mathrm{~mm}$ thick) was annealed at $950^{\circ} \mathrm{C}$ for $1 \mathrm{hr}$ and then etched in hydrofluoric acid (1\% HF and 40\% HF) during $1 \mathrm{~min}$. The XPS measurements were performed on initial and etched $c p$-Ti samples using a Perkin Elmer PHI $5600 \mathrm{ci}$ Multitechnique System with monochromatized $\mathrm{Al} \mathrm{K \alpha}$ radiation (FWHM $=0.3 \mathrm{eV}$ ). The XPS binding energies of untreated $c p$-Ti, given in Table 1, were determined using the $\mathrm{Au} 4 f_{7 / 2}$ core level $\left(E_{b}\left(\mathrm{Au} 4 f_{7 / 2}\right)=84.0 \mathrm{eV}\right)$ as a reference. For each set of XPS measurements the ion etching (with $\mathrm{Ar}^{+}$ions) was performed step by step with intervals of few minutes (from $1 \mathrm{~min}$ to $10 \mathrm{~min}$ ).

\section{Results and Discussion}

XPS wide scans of coarse-grained $c p$-Ti before and after chemical treatment in hydrofluoric acid ( $1 \%$ and $40 \% \mathrm{HF})$ are presented in Figure 2. The XPS analysis shows, that dental implant surfaces consist of titanium, oxygen and carbon. As can be seen (Figure 2 and Table 2), C/Ti intensity ratio estimated from XPS survey spectra decreased from 6.3 to 5.3 after treatment in $1 \% \mathrm{HF}$ (for $1 \mathrm{~min}$ ) and from 6.3 to 2.9 after treatment in $40 \% \mathrm{HF}$ (for $1 \mathrm{~min}$ ). Therefore, the acid treatment reduces the contamination of $c p$-Ti surface with hydrocarbons, and increases the surface energy and potential bio-compatibility of the Tiimplant.

The concentration profiles of carbon, oxygen and titanium on the surface of untreated and chemically treated $c p$-Ti (Figure 3) show, that the acid etched surface is much cleaner than the untreated surface. The carbon contamination for the acid etched surface is much lower and the oxygen concentration is much higher than for the untreated sample. The curves of the acid etched surface are much flatter than those of the untreated surface, what means that the oxide in the near-surface region is much more homogeneous than in the untreated sample. The surface contamination of the acid treated sample can practically be removed within very few sputter cycles, whereas for the untreated sample the contamination reaches deeper into the bulk.

According to XPS measurements of high-energy resolved Ti $2 p_{3 / 2,1 / 2}$ spectra (Figure 4 ), the Ti $2 p_{3 / 2}$ and Ti $2 p_{1 / 2}$ peaks are located at $459.2 \mathrm{eV}$ and $464.9 \mathrm{eV}$ both before and after acid treatment and can be attributed to $\mathrm{Ti}^{4+}[5]$. No $\mathrm{Ti}^{3+}$ shoulder at lower binding energy on the Ti $2 p_{3 / 2}$ peak is detected, suggesting that all samples have a stoichiometric $\mathrm{TiO}_{2}$ surface. As can be seen, XPS Ti $2 p$ spectra consist of high-energy shake up satellites at 477.8 $\mathrm{eV}$ and $472.4 \mathrm{eV}$ which are typical for $\mathrm{TiO}_{2}$ [6]. It is in

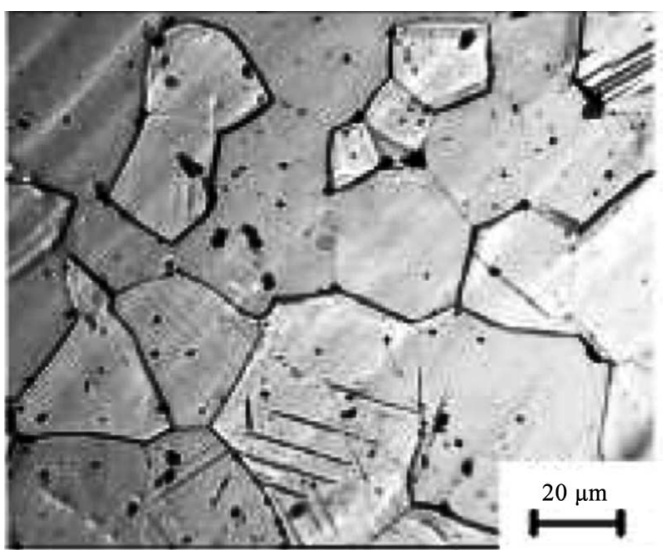

Figure 1. Microstructure of the initial coarse grained $c p$-Ti.

Table 1. XPS binding energies of untreated $c p$-Ti.

\begin{tabular}{ccc}
\hline Core level & Binding energy $^{\mathrm{a}}(\mathrm{eV})$ & FWHM $(\mathrm{eV})$ \\
\hline Ti $2 s$ & 561.4 & \\
Ti $2 p_{1 / 2}$ & 460.8 & 1.3 \\
Ti $2 p_{3 / 2}$ & 454.7 & 2.0 \\
Ti $3 s$ & 59.1 & \\
Ti $3 p$ & 34.0 & \\
O $1 s$ & 531.4 & 1.1 \\
O $2 s$ & 23.5 & \\
\hline
\end{tabular}

${ }^{\mathrm{a}}$ Reference: $E_{B}\left(\mathrm{Au} 4 f_{7 / 2}\right)=84.0 \mathrm{eV}$.

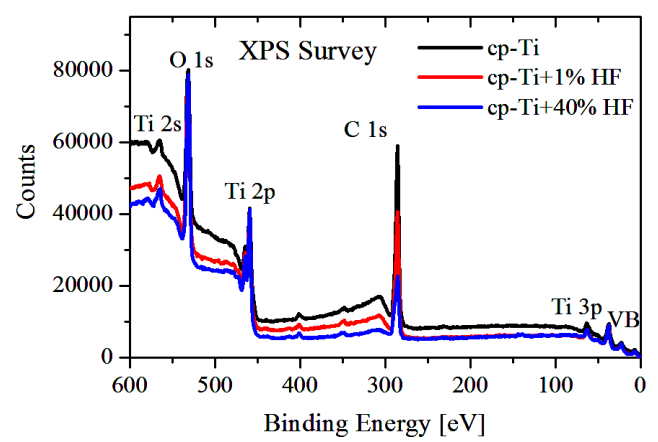

Figure 2. XPS wide scans of coarse-grained $c p$-Ti before and after chemical treatment in hydrofluoric acid $(1 \%$ and $40 \% \mathrm{HF})$.

Table 2. Concentration of Ti, $\mathrm{C}$ and $\mathrm{O}$ estimated from highenergy resolved XPS spectra.

\begin{tabular}{|c|c|c|c|c|}
\hline Sample & $\mathrm{Ti}(\mathrm{at} \%)$ & $\mathrm{O}(\mathrm{at} \%)$ & $\mathrm{C}(\mathrm{at} \%)$ & $\mathrm{O} / \mathrm{Ti}$ ratio $(\mathrm{at} \%)$ \\
\hline $\begin{array}{c}c p-\mathrm{Ti}, \\
\text { without } \\
\text { treatment }\end{array}$ & 9.8 & $\begin{array}{c}28.2 \\
(13.4 / 14.8) \\
\text { (shoulder/peak) }\end{array}$ & 62.0 & $14.8 / 9.8=1.51$ \\
\hline $\begin{array}{l}c p-\mathrm{Ti} \\
1 \% \mathrm{HF} \\
1 \mathrm{~min}\end{array}$ & 10.7 & $\begin{array}{c}32.5 \\
(14.3 / 18.2) \\
\text { (shoulder/peak) }\end{array}$ & 56.8 & $18.2 / 10.7=1.70$ \\
\hline $\begin{array}{c}c p-\mathrm{Ti} \\
40 \% \mathrm{HF}, \\
1 \mathrm{~min}\end{array}$ & 13.8 & $\begin{array}{c}46.3 \\
(23.2 / 23.1) \\
\text { (shoulder/peak) }\end{array}$ & 39.9 & $23.1 / 13.8=1.67$ \\
\hline
\end{tabular}




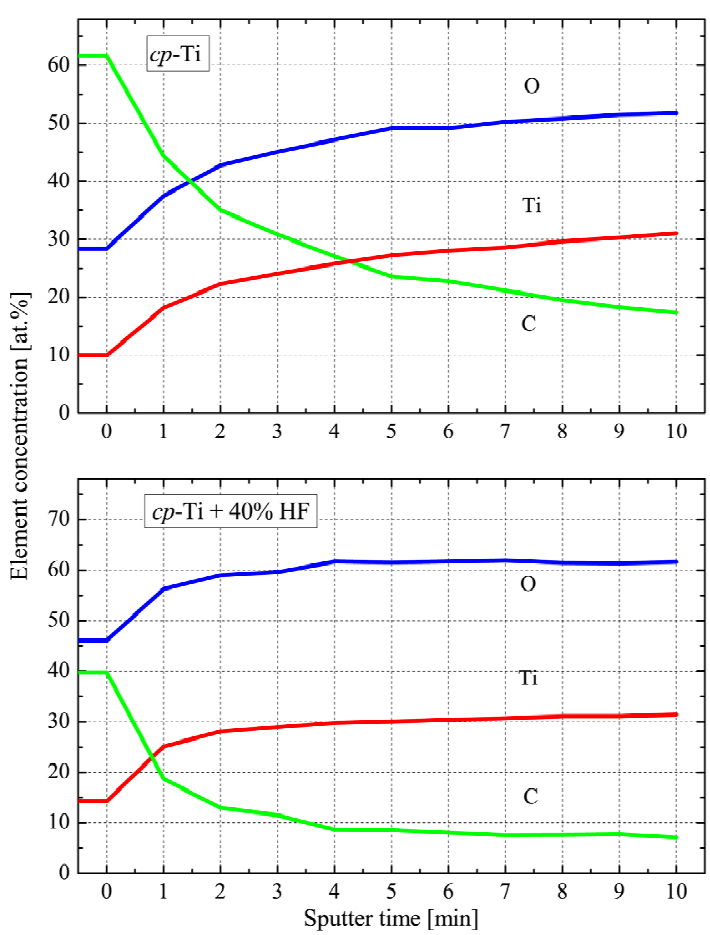

Figure 3. The concentration profiles of carbon, oxygen and titanium on the surface of untreated and chemically treated cp-Ti.

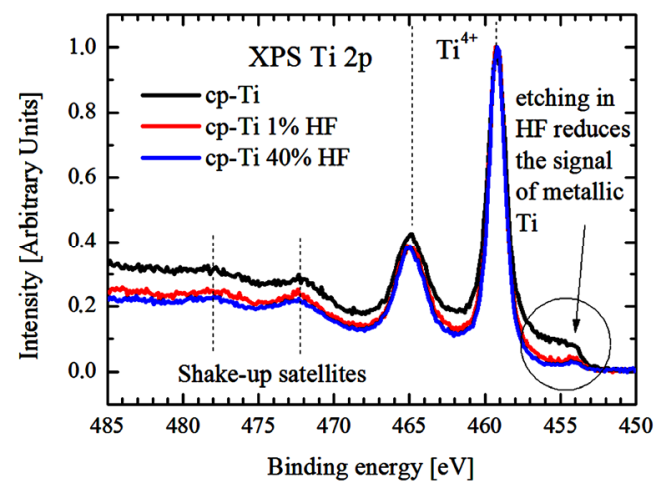

Figure 4. XPS Ti $2 p$-spectra of initial and acid treated $c p$-Ti.

agreement with the theoretical thermodynamics, which specify, that the free energy of formation of $\mathrm{TiO}_{2}$ is favored over other titanium oxides [7]. XPS Ti $2 p$ spectra of untreated and chemically treated $c p$-Ti measured depending on time of $\mathrm{Ar}^{+}$-ion etching ( $\left.1 \mathrm{~min}-10 \mathrm{~min}\right)$ are found to be quite different (Figure 5). One can see, that the near- surface region of untreated $c p$-Ti is composed by superposition of $\mathrm{TiO}_{2}, \mathrm{Ti}_{2} \mathrm{O}_{3}, \mathrm{TiO}$ and Ti-metal, whereas the contributions of $\mathrm{Ti}_{2} \mathrm{O}_{3}, \mathrm{TiO}$ and $\mathrm{Ti}$-metal are strongly reduced for chemically treated sample. It means that the $\mathrm{TiO}_{2}$ concentration in the surface region of the acid treated sample is significantly higher than in the untreated sample.

Figures 6 and 7 display the high-resolution XPS C $1 s$

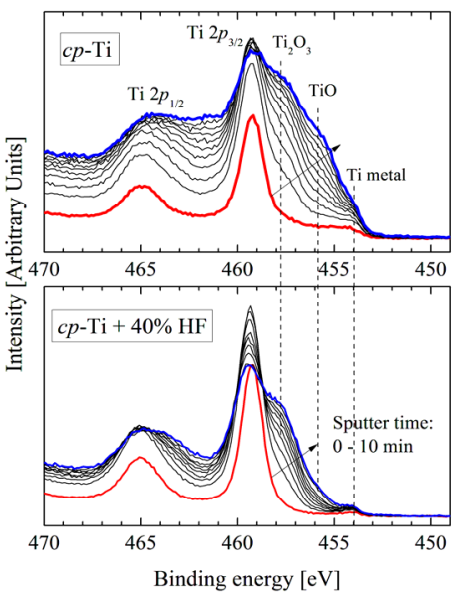

Figure 5. XPS Ti $2 p$-spectra of untreated (upper panel) and chemically treated (lower panel) $c p$-Ti in dependence of etching time.

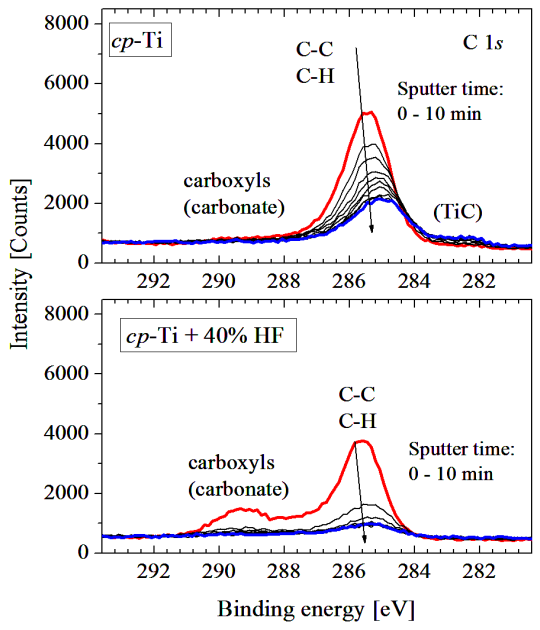

Figure 6. XPS C 1s spectra of initial (upper panel) and acid treated (lower panel) $c p$ - $\mathrm{Ti}$ in dependence of time etching.

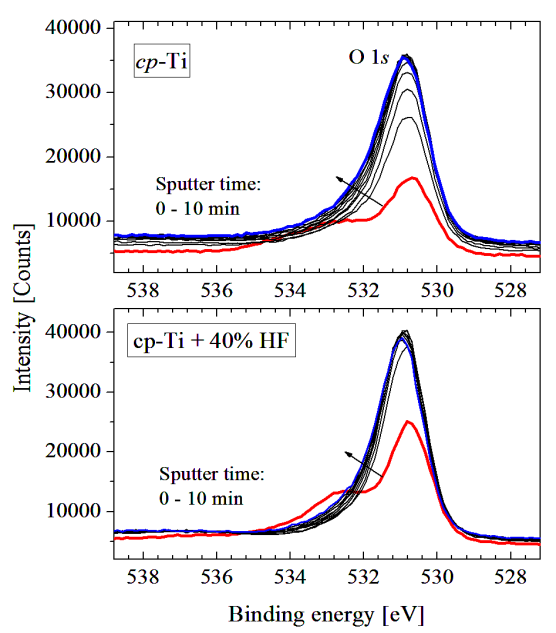

Figure 7. XPS O 1s spectra of untreated (upper panel) and chemically treated (lower panel) $c p$-Ti in dependence of time etching. 
and $\mathrm{O} 1 \mathrm{~s}$ core levels spectra of initial and chemically treated $c p-\mathrm{Ti}$ in dependence of $\mathrm{Ar}^{+}$-ion etching. One can see that the hydrocarbons (C-C, $\mathrm{C}-\mathrm{H})$ give the main contribution to the $\mathrm{C} 1 \mathrm{~s}$ peak, while the less intensive high energy shoulder is formed by carboxyl/carbonate groups [8] (Figure 6). Chemical treatment strongly reduces carbon contamination especially in the near-surface region.

Both initial and treated $c p$-Ti samples show an intensive $\mathrm{O} 1 \mathrm{~s}$ peak from Ti-O bonds at $530.6 \mathrm{eV}$ and a shoulder at higher energy which can be attributed to the contributions of $\mathrm{OH}$ and $\mathrm{H}_{2} \mathrm{O}$ species [9], the content of which is not strongly changed after chemical treatment (Figure 7). One can see, that $\mathrm{O} 1 \mathrm{~s}$ signal is not practically reduced with the ion etching giving additional evidence of formation of thick $\mathrm{TiO}_{2}$ layer on the surface of chemically treated $c p$-Ti. It has been suggested, that the hydroxyl groups contribute to bone growth because calcium ions bind with the acidic groups and phosphate molecules bind with the basic groups of hydroxyapatite [8].

XPS F $1 s$ spectra of $c p$-Ti after chemical treatment in HF (not shown) are found to be very similar to those of Ti immersed in solution containing fluoride [10]. The formation of titanium fluoride $\left(\mathrm{TiF}_{4}\right)$ on the surface of $c p$ Ti after acid treatment is not clearly detected.

In Figure 8 the XPS valence bands of initial and chemically treated $c p-\mathrm{Ti}$ are presented. They consist of four peaks located at $14.5 \mathrm{eV}, 7.4 \mathrm{eV}, 5.5 \mathrm{eV}$ and $0.9 \mathrm{eV}$. In agreement with previous studies we assign the feature located at $7.4 \mathrm{eV}$ to $\mathrm{O} 2 p$-Ti $3 d$ hybridized states, while the $5.5 \mathrm{eV}$ feature has mainly $\mathrm{O} 2 p$ character [11]. One can see, that the ratio of the two peaks located at 7.4 and $5.5 \mathrm{eV}$ is found to be very similar to that of $\mathrm{TiO}_{2}$ [5]. C $2 s$-states are fixed at $\mathrm{E}=14.5 \mathrm{eV}$ and are seen mainly in the spectrum of untreated $c p$-Ti where the contribution of carbon contamination is the highest (see Figures $\mathbf{1}$ and 5). The peak at $0.9 \mathrm{eV}$ can be attributed to a contribution of $3 d$-states of metallic $\mathrm{Ti}$ [12]; the relative intensity of this peak is not changed after etching which is consistent with XPS Ti $2 p$-measurements (see Figure 3).

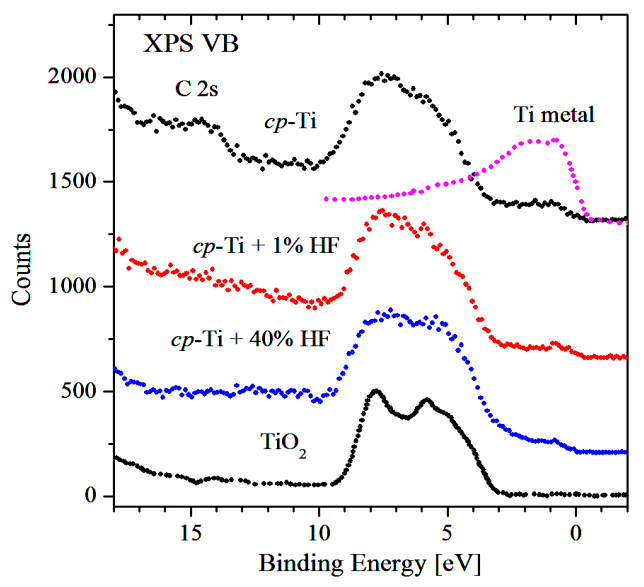

Figure 8. XPS valence bands of initial and acid treated $c p$-Ti.

\section{Conclusion}

To conclude, we have performed a full surface characterization of commercially pure $\mathrm{Ti}(c p-\mathrm{Ti})$ before and after chemical treatment in hydrofluoric acid with help of the XPS measurements of core levels and valence bands. It is found, that after acid treatment the content of hydrocarbons is reduced, what increases the surface energy and potential of bio-acceptability of a Ti-implant. According to our measurements, the acid treatment reduces the level of surface contaminations and induces the formation of thick $\mathrm{TiO}_{2}$ oxide layer.

\section{Acknowledgements}

We acknowledge the support of the Russian Science Foundation for Basic Research (Project 11-02-00022).

\section{REFERENCES}

[1] D. C. Smith, "Surface Characterization of Implant Materials: Biological Implications," In: J. E. Davies, Ed., The Bone-Biomaterial Interface, University of Toronto Press, Toronto, 1991, pp. 3-18.

[2] B. Kasemo and J. Lausmaa, "Metal Selection and Surface Characteristics," In: P.-I. Branemark, G. A. Zarb and T. Alberktsson, Eds., Tissue-Integrated Prostheses: Osseointegration in Clinical Dentistry, Quintessence, Chicago, 1985, pp. 99-116.

[3] J. E. Ellingsen, C. B. Johansson, A. Wennerberg and A. Holmen, "Improved Retention and Bone-to-Implant Contact with Fluoride-Modified Titanium Implants," The International Journal of Oral \& Maxillofacial Implants, Vol. 19, No. 5, 2004, pp. 659-666.

[4] J. E. Ellingsen, "Pre-Treatment of Titanium Implants with Fluoride Improves Their Retention in Bone," Journal of Materials Science: Materials in Medicine, Vol. 6, No. 12, 1995, pp. 749-753. doi:10.1007/BF00134312

[5] S. Bartkowski, M. Neumann, E. Z. Kurmaev, V. V. Fedorenko, S. N. Shamin, V. M. Cherkashenko and S. N. Nemnonov, A. Winiarski and D. C. Rubie, "Electronic Structure of Titanium Monoxide," Physical Review B, Vol. 56, No. 16, 1997, pp. 10656-10667. doi:10.1103/PhysRevB.56.10656

[6] H. B. Jones, "Teeth and Bones: Application of Surface Science to Dental Materials and Related Biomaterials," Surface Science Report, Vol. 42, No. 3-5, 2001, pp. 75205. doi:10.1016/S0167-5729(00)00011-X

[7] C. M. Chan, S. Trigwell and T. Ouerig, "Oxidalion of a NiTi Alloy," Surface and Interface Analysis, Vol. 15, No. 6, 1990, pp. 349-354. doi:10.1002/sia.740150602

[8] Y.-J. Park, H.-J. Song, I. Kim and H.-S. Yang, "Surface Characteristics and Bioactivity of Oxide Film on Titanium Metal Formed by Thermal Oxidation," Journal of Materials Science: Materials in Medicine, Vol. 18, No. 4, 2007, pp. 565-575. doi:10.1007/s10856-007-2303-7

[9] J.-H. Yi, C. Bernard, F. Variola, S. F. Zalzal, J. D. Wuest, F. Rosei and A. Nanci, "Characterization of a Bioactive Nanotextured Surface Created by Controlled Chemical 
Oxidation of Titanium," Surface Science, Vol. 600, No. 19, 2006, pp. 4613-4621. doi:10.1016/j.susc.2006.07.053

[10] S. Takemoto, M. Hattori, M. Yoshinari, E. Kawada and Y. Oda, "Suppression of Fluoride-Induced Corrosion of Titanium by Albumin in Oral Modified Environment," Journal of Biomedical Materials Research Part B: Applied Biomaterials, Vol. 87, No. 2, 2008, pp. 475-481. doi:10.1002/jbm.b.31129
[11] U. Diebold, "The Surface Science of Titanium Dioxide," Surface Science Reports, Vol. 48, No. 5-8, 2003, pp. 53-229. doi:10.1016/S0167-5729(02)00100-0

[12] H. Höchst, P. Steiner, G. Reiter and S. Hüfner, "XPS Valence Bands of Ti, Zr, Nb, Mo and Hf," Zeitschrift für Physik B Condensed Matter, Vol. 42, No. 3, 1981, pp. 199-204. doi:10.1007/BF01422023 